\title{
Robustness and energy absorption capacity of laterally unrestrained reinforced concrete slabs
}

\section{Conference Paper}

\section{Author(s):}

Herraiz, Borja; Vogel, Thomas

Publication date:

2015

Permanent link:

https://doi.org/10.3929/ethz-a-010433538

Rights / license:

In Copyright - Non-Commercial Use Permitted

Originally published in:

https://doi.org/10.1061/9780784479117.011 


\section{$i|b| k$}

Institute of Structural Engineering

Structural Engineering

Structural Design and Conservation
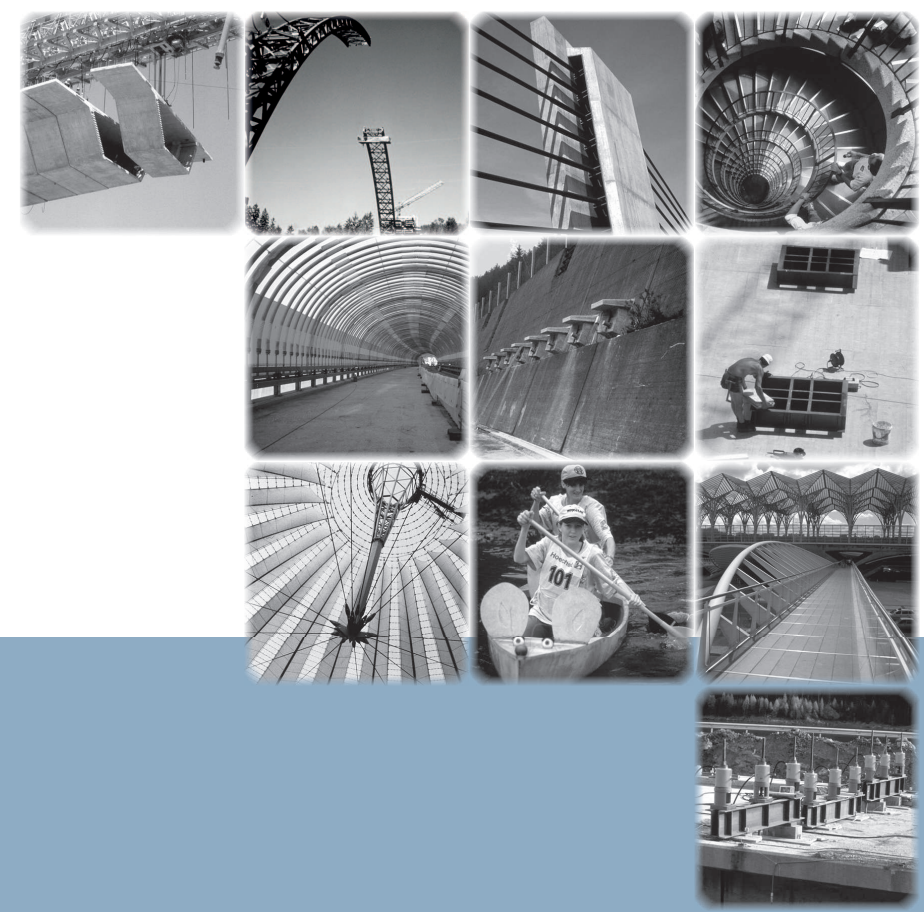

Title:

Robustness and energy absorption capacity of laterally unrestrained reinforced concrete slabs

American Society of Civil Engineers

Portland, Oregon

Publication Dat:

Nathan Ingraffea, Mark Libby

Proceedings of the Structures Congress

Structures Congress 2015

Portland, Oregon

April 23-25, 2015

03353 


\title{
Robustness and energy absorption capacity of laterally unrestrained reinforced concrete slabs
}

\author{
B. Herraiz ${ }^{1}$ and T. Vogel $^{2}$ \\ ${ }^{1}$ Institute of Structural Engineering (IBK), Swiss Federal Institute of Technology \\ Zurich (ETH), Stefano-Franscini-Platz 5, CH-8093, Zurich, Switzerland; PH +41 44 \\ 63331 43; FAX +41 4463310 64; email: herraiz@ibk.baug.ethz.ch \\ ${ }^{2}$ Institute of Structural Engineering (IBK), Swiss Federal Institute of Technology \\ Zurich (ETH), Stefano-Franscini-Platz 5, CH-8093, Zurich, Switzerland; PH +41 44 \\ 633 31 34; FAX +41 4463310 64; email: vogel@ibk.baug.ethz.ch
}

\begin{abstract}
The structural robustness of buildings is related to their capacity to redistribute loads after a local failure preventing progressive collapse. The energy absorption capacity of structural elements allows estimating both, their static and dynamic loadbearing capacities and therefore is a key parameter for robustness assessments. This paper presents a methodology to calculate the static load-deflection relationship of laterally unrestrained reinforced concrete (RC) slabs by means of three different stages: an elastic stage, a transitional elastic-plastic stage and a membrane action stage. Membrane forces are estimated from the kinematic relationships of the slab and equilibrium considerations. This approach includes different failure criteria in order to estimate the total energy absorption capacity of these slabs.
\end{abstract}

\section{INTRODUCTION}

Recent and past progressive collapse events such as Ronan Point, London 1968, Alfred Murrah Building, Oklahoma 1995 and World Trade Center, New York 2001 have underlined the necessity of enhancing the structural redundancy and damage tolerance of buildings. Robustness is usually defined as a property of a structure to resist a localized failure without suffering damage disproportionate to the event that caused it. Several investigations have been performed during these last decades in order to find a normalized procedure to design and evaluate the robustness of buildings. One of the most accepted approaches, implemented by several international design codes (ASCE 7-10 2010), (Department of Defense of the U.S.A. 2005), (U.S. General Services Administration 2003), (European Committee for Standardization 2006), 
consists in ensuring that the building can survive the accidental sudden removal of a column. The performance of the structure subjected to this event highly depends on the dynamic response of the directly affected bay, as collapse will spread from it throughout the building. This response is significantly related to its energy absorption capacity as it allows estimating the ultimate load-bearing capacity and performing robustness assessments (Herraiz, B. and Vogel, T. 2014). The present investigation is focused on laterally unrestrained RC slabs. The assumption of no lateral restraint corresponds to the lack of horizontal stiffness of common flat slabs and the inability to develop full arching and catenary action (Herraiz, B. and Vogel, T. 2014).

\section{BEHAVIOUR OF LATERALLY UNRESTRAINED RC SLABS}

Laterally unrestrained RC slabs subjected to an increasing uniform load show a complex behaviour along the deformation process. At low loads, the slab behaves elastically and the flexural rigidity governs the response. After cracking, a redistribution of moments occurs due to the drop of stiffness in the cracked sections.

For increasing loads, cracks widen, shifting the neutral axis of the cross sections and producing a lateral expansion of the slab. Some regions reach their yield moment. A complex elastic-plastic behaviour governs the response at this stage. The maximum capacity is reached for a further increase of the loads, defining a collapse mechanism and segmenting the slab into stiff regions. At this moment, deflections increase and the expansion rate of the slab is reduced until it begins to shrink. Contrary to the lateral expansion of the slab, this inwards movement is restrained by the slab itself. Contact between the slab segments occurs and self-balanced membrane forces develop increasing the load-bearing capacity of the slab. Tensile membrane forces are created inside an internal ellipse around the slab centre while an outer compressive ring develops along the slab's supports (see Figure 1).

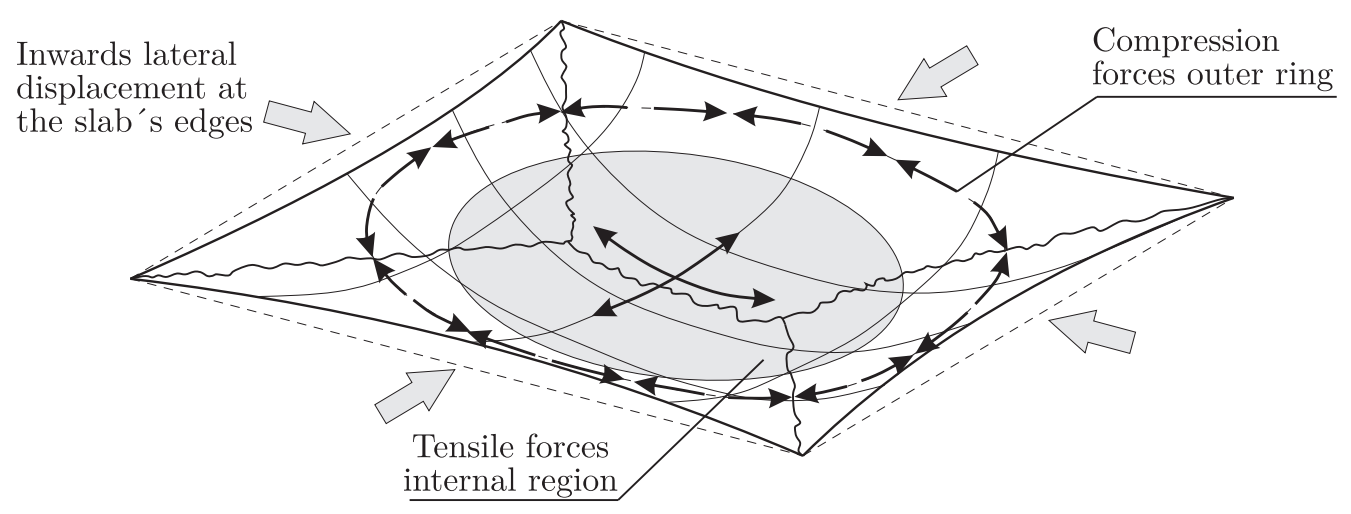

Figure 1. Development of membrane forces in laterally unrestrained RC slabs 
The kinematic incompatibility of these lateral inwards displacements with the existing collapse mechanism causes the development of a crack perpendicular to the longer side of the slab so the deformation process can continue. This tensile crack and corresponding forces begin to develop at the centre of the slab and expand for increasing deflections, being balanced by the compression forces close to the edges. This tensile-compression forces interaction results in an in-plane bending similar to a scissors mechanism: the slab segments rotate about a vertical axis at the in-plane bending plastic hinge at the compressed zone next to the edges (see Figure 2). Membrane forces are therefore a result of a complex interaction between the kinematics of the slab and equilibrium of forces and in-plane bending moments.

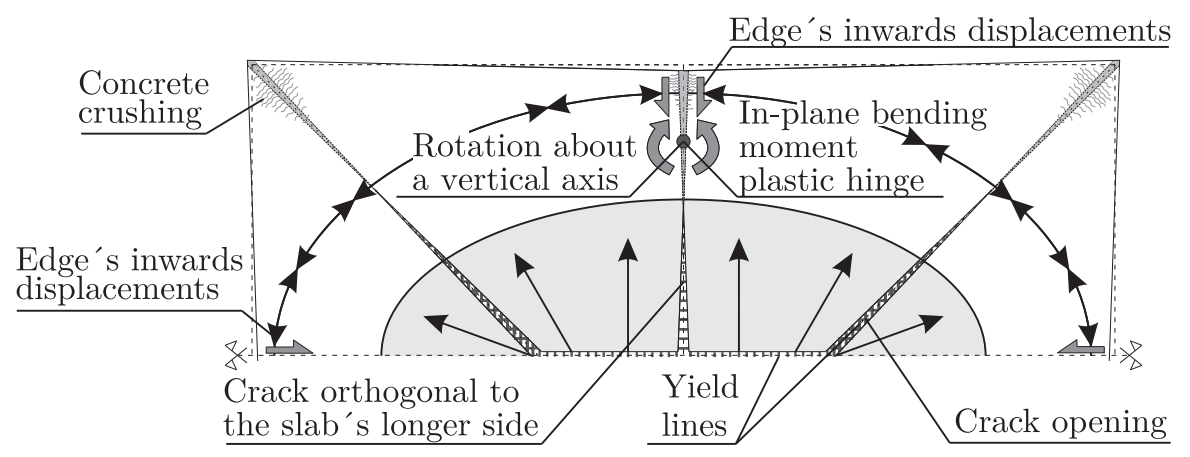

Figure 2. In plane bending moments due to membrane forces

The flexural capacity of the slab is enhanced for increasing deflections due to the membrane forces. Hence, the slab can bear increasing loads until failure occurs:

- compressive failure due to concrete crushing at the outer ring

- failure at the axial crack due to reinforcement rupture when reaching the ultimate strain of the material

\section{EXISTING APPROACHES}

The energy absorption capacity is directly related to the load-deflection relationship. This relationship is not easy to determine due to the development of membrane forces. Besides, it is difficult to set reliable and effective failure criteria due to the complex interactions occurring during the deformation process.

First efforts to describe these phenomena were done during the mid-1960s. Theoretical work, experimental campaigns (see Figure 3) and the development of analytical solutions were performed by different authors (Sawczuk, A. and Winnicki, L. 1965), (Kemp K. O. 1967) and (Hayes, B. 1968).

These experiments show that the collapse pattern corresponding to conventional yield line theory remains constant during the deflection process even for large 
deflections once membrane forces are developed. Additionally, a full-depth axial crack (or cracks) develops perpendicular to the longer span of the slab, through which the reinforcement is likely to rupture. Most of these first analytical solutions did not consider equilibrium and kinematics together. Furthermore, any of them include a failure criterion to limit the capacity of the slab.
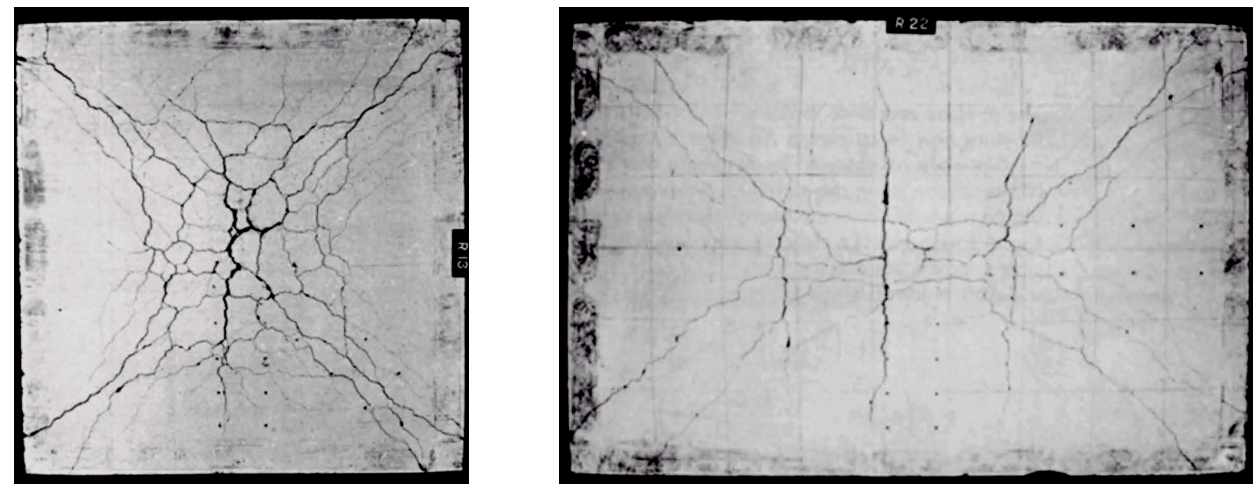

Figure 3. Tests performed by Hayes (Hayes, B. 1968)

During decades, the research on this topic was abandoned until recent years, when it has gained renewed relevance as the reserve of strength can play a very significant role in progressive collapse scenarios. In this direction, Bailey (Bailey, C.G. 2001) (Bailey, C. G. and Toh, W. S. 2007) has performed experimental, analytical, and design related research, investigating the influence of reinforcement orthotropy, steel-concrete bond and aspect ratio of the slab for its ultimate capacity. The approach proposed by Bailey is a modification of the one by Hayes, but includes two semi-empirical conservative failure criteria: rupture of reinforcement based on the average strain along the length of the slab and compressive failure of concrete at the slab's corners based on the compressive stress-block depth.

Further research was performed recently by Cashell (Cashell, K.A. 2009). Cashell investigated the response of laterally unrestrained slabs focusing on the impact of steelconcrete bond on its ultimate capacity. Cashell considers two failure criteria: reinforcement rupture based on the bond-slip relationship and compressive failure of concrete at the edge's mid-point based on the concrete's stress-block depth.

All these approaches only describe the post-yielding behaviour of the slab and they do not consider the kinematic and equilibrium relationships together. On the other hand, analyses based on the Finite Element Method (FEM) are able to represent the response of the slab, but they cannot effectively represent the interaction between concrete and steel at cracks and are inadequate for the prediction of failure.

Alternatively, a new simple approach based on both, kinematics and equilibrium, which include the different previously described failure criteria, has been developed. 


\section{NEW PROPOSED APPROACH}

The following method is valid for laterally unrestrained rectangular RC slabs with orthotropic orthogonal reinforcement subjected to uniform vertical loading. The slabs can be simply supported or rotationally restrained along the supports. A perfect rigidplastic mechanism has been used for calculating the kinematic relationships. Only in the first stage of the approach the elastic deformations have been considered. This method divides the load-deflection relationship in three stages (see Figure 4):

- The first stage comprises the elastic range.

- The second stage is a transitional stage between the pure elastic and plastic behaviour of the slab

- The third stage comprises the development of membrane action.

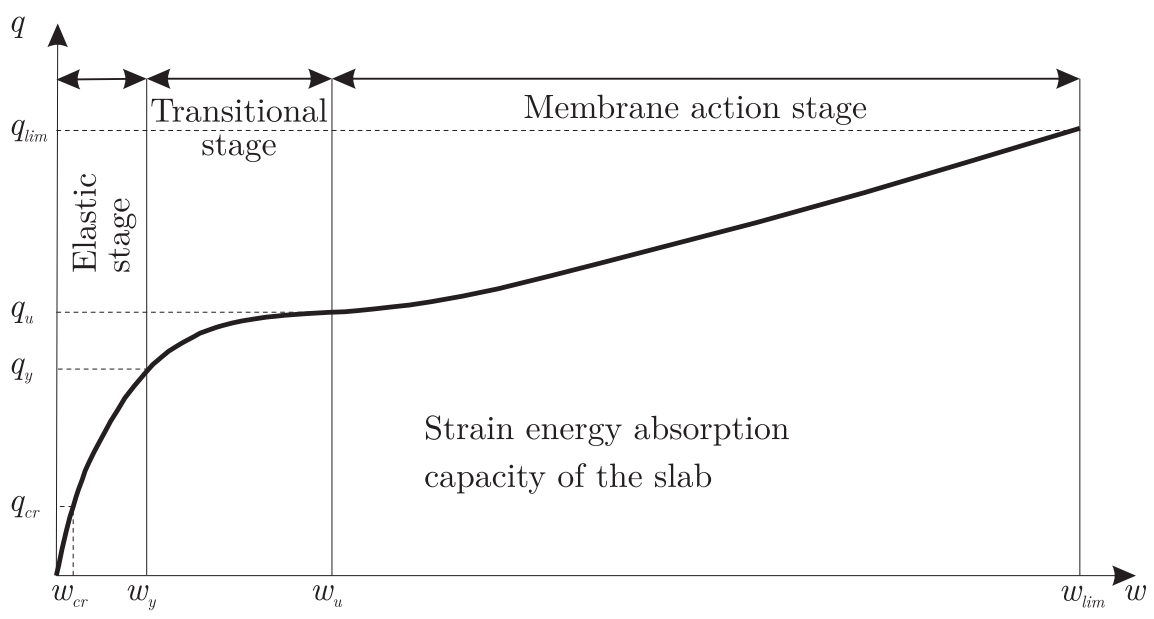

Figure 4. Load-deflection relationship proposed by the new approach

\section{Elastic Stage}

During this first stage, the flexural rigidity governs the behaviour of the slab. At this stage, the load-deflection relationship is calculated from classic elastic analysis. This relationship is valid until the yield moment of the slab is reached.

The approach is a modification of an existing method (Vanderbilt M. D., Sozen M. A. and Siess C. P. 1963) and accounts for concrete cracking. This approach considers that, for low loads up to causing the initial cracks, the deflections are computed using the average un-cracked rigidity of the slab. The deflections at the load causing the first yielding of reinforcement are calculated with an average partially-cracked rigidity of the slab considering the cracked and un-cracked areas of the slab. Finally, a parabolic transition between these two points is assumed to compute deflections at intermediate loads. 


\section{Transitional Stage}

The transitional stage comprises the intermediate behaviour of the slab from the end of the elastic range when the yield moment is reached, to the pure plastic range once the collapse mechanism has totally developed and tensile membrane action starts. Along this stage, complex interactions occur, leading to a cumbersome elastic-plastic behaviour difficult to describe. Moreover, the lateral expansion of the slab may produce the development of compression membrane forces through arching action and the formation of a tensile ring along the edges. Due to the lack of horizontal stiffness of laterally unrestrained slabs, the effect of these compressive membrane forces is small and it has been neglected in this stage.

This short transitional stage does not have a great impact on the total strain energy absorption capacity of the slab. Hence, an exponential function for the load-deflection relationship, $q\left(w_{0}\right)=-e^{-A w_{0}+B}+C$, is assumed. In order to set this curve, the following parameters must be defined:

- The yielding load $q$, the yielding deflection $w_{y}$ and the corresponding slope, which are calculated at the end of the previous elastic stage.

- The ultimate load $q_{u}$, which corresponds to the minimum load necessary to create the collapse mechanism. This load sets the value of the horizontal asymptote as it is, in theory, the maximum load-carrying capacity of the slab disregarding in-plane forces. This load and the corresponding yield line pattern are calculated applying the rules and assumptions of the classic yield line theory (Johansen K. W. 1943).

- The ultimate deflection $w_{u}$, which is the deflection for which the slab's edges change from moving outwards to inwards, defining the extension of the transitional stage. It is determined by the kinematic relationships.

The kinematic relationships of the slab are defined by means of a rigid perfectlyplastic model (see Figure 5). This model assumes that the yield lines are perfect-plastic line hinges which allow free rotation along them and each slab segment is a nondeformable rigid element. Furthermore, a crack along the shorter span has been implemented into the kinematic model, allowing lateral displacements. It is assumed that the adopted yield collapse mechanism does not change for increasing deflections.

The following kinematic relationships and model are valid for both, transitional and membrane action stage. It is important to note the difference between the neutral axis for pure bending and the neutral axis once membrane forces develop. The parameter $\mu(y)$ represents the relative variation of concrete depths that occurs along the yield lines between the previously defined axes in this kinematic model. In order to apply this kinematic model for the transitional stage, where there are not axial forces, the kinematic relationships are particularized so that $\mu(y)$ is equal to zero. 
In order to obtain the ultimate load, the kinematic relationships along Section A-A of Figure 5 and further geometric relationships that allow linking the mid-crack opening with the lateral displacements of the slab's edges has been considered. Finally, the deflection for the slab's edges to change the direction of movement from inwards to outwards, is the one given by the following expression:

$$
w_{0}=d_{r}
$$

Hence, for this simplified approach, the membrane forces develop for vertical deflections larger than the rotational depth of the neutral axis $\left(d_{r}\right)$.

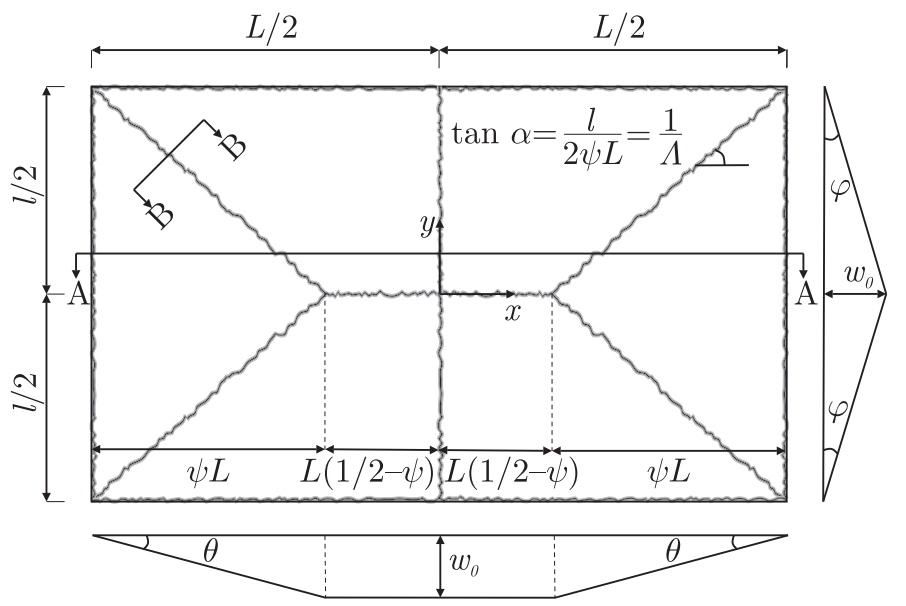

Section B-B

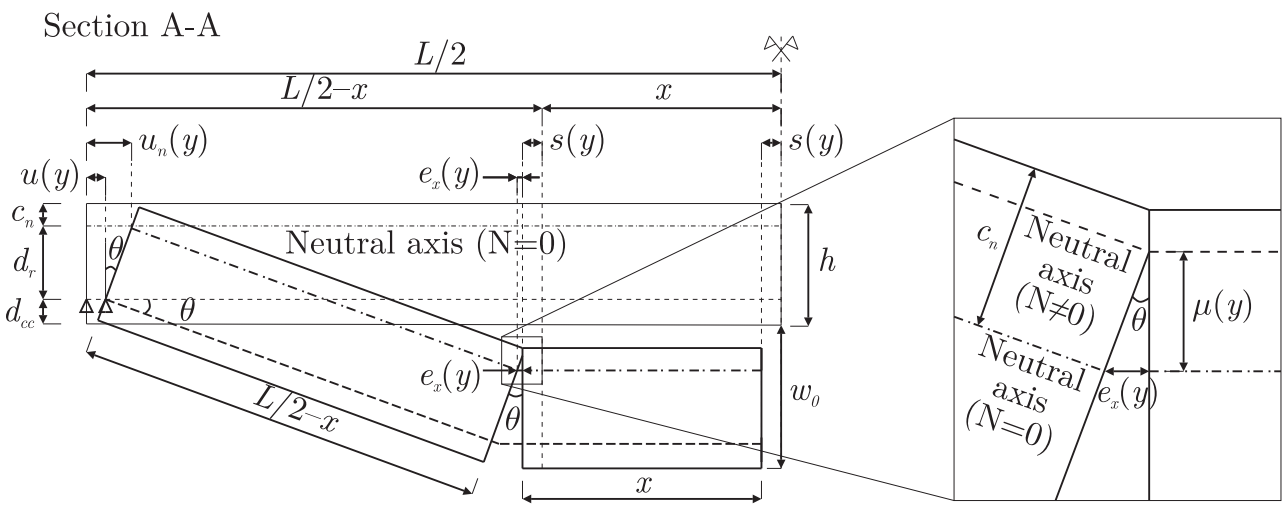

Figure 5. Rigid perfectly-plastic kinematic slab model

\section{Membrane Action Stage}

The membrane action stage represents the final phase of the load-deflection relationship of the slab, from the start of the development of tensile membrane action until failure. For every deflection increase, the membrane forces distribution in the slab and the correspondent enhance in the load-bearing capacity is estimated by considering kinematics and equilibrium. 
The kinematic relationships and model are the same as the one used for the transitional stage but considering the relative variation of the concrete depths along the yield lines with respect to the neutral axis for pure bending, which is characterized by the parameter $\mu(y)$ (see Figure 5). It can be demonstrated that, for the assumed rigid body displacements and rotations, the neutral axes for the membrane action stage along the yield lines are straight lines. Hence, the variation of concrete depths along them is also linear and can be expressed as follows:

$c(y)=c_{n}-\mu(0)\left(1-\frac{y}{y_{0}}\right)$

The distribution of concrete depths $c(y)$ along the yield lines can be set through two unknown parameters: $\mu(0)$ and $y_{0}$. The equilibrium of the in-plane internal forces of the slab along the deformation process provides the two necessary relationships to fix these parameters. Based on the yield criterion of bilinear elastic-perfectly plastic materials, the ultimate capacity for a reinforced concrete section subjected to combined bending and axial load is defined by the level of the neutral axis. Hence, the concrete depths directly define the membrane forces along the yield lines for the ultimate capacity and therefore there is not a direct solution for the parameters $\mu(0)$ and $y_{0}$, which must be solved numerically using an iterative procedure.

As it has been previously explained, it is necessary to determine the equilibrium relationships of the in-plane internal forces of the slab. These in-plane forces are depicted in Figure 6 for a generic deformation state of the slab.

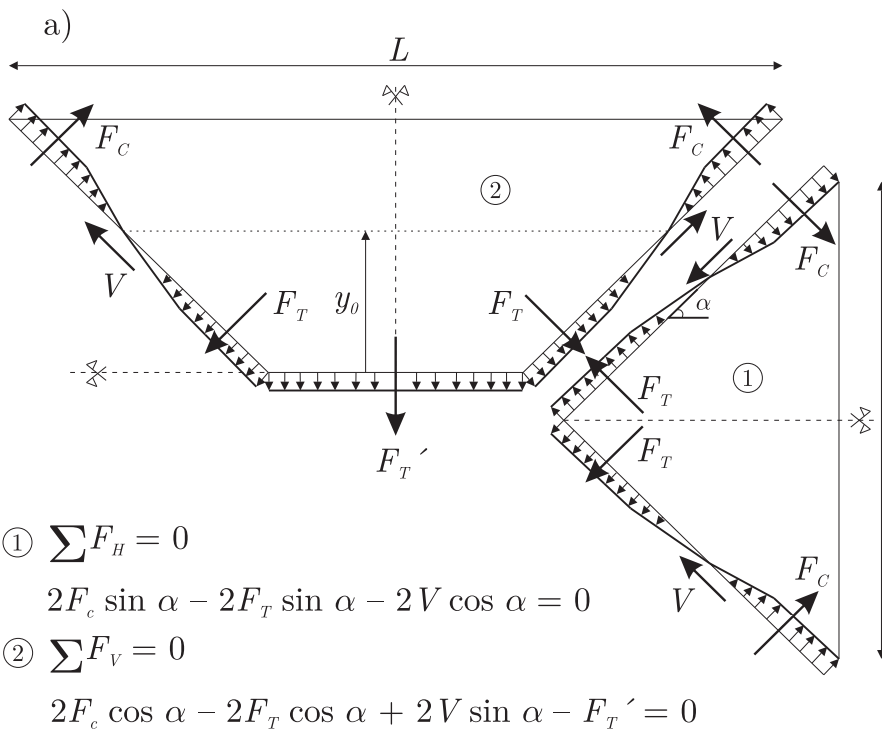

b)

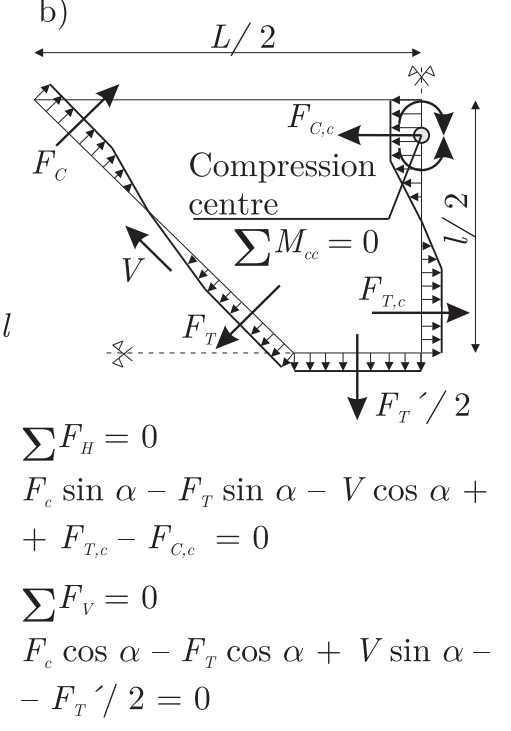

Figure 6. a) In-plane equilibrium of the slab; b) In-plane equilibrium of a trapezoidal segment of the slab including the axial mid-crack 
For equilibrium in the $x$ - and $y$-direction of the triangular and the trapezoidal slab segments, the following relationship is obtained:

$$
F_{c}-F_{T}=\frac{F_{T}^{\prime}}{2} \cos \alpha
$$

This expression links the membrane forces along the yield lines and provides the first equilibrium condition for the two unknowns. Additionally, balancing forces of the trapezoidal segment with the axial mid-crack lead to the following expression:

$$
F_{T, c}=F_{C, c}
$$

This expression states that normal forces must also be balanced along the midcrack and it is used to set the distribution of axial forces.

The second equilibrium equation is derived from the previously described phenomena observed in experimental tests consisting on an in-plane rotation. This is implemented in the approach by imposing equilibrium of in-plane bending moments produced by the internal forces along the mid-crack and yield lines at the mid-crack's compression center:

$$
\sum M_{c c}=0
$$

In order to fulfill this last equation, the axial forces along the mid-crack must be determined. These forces are estimated through the distribution of axial strains by means of the constitutive material relationships. The distribution of axial strains is assumed to be different for the compression and the tensile zone of the mid-crack.

The axial strains are considered to be linearly distributed for the compression zone, assuming that plane sections remain plane along the deformation process. For the tensile zone, the strains are assumed to be linked to the crack opening displacements. Since the effect at the crack opening is similar to a pull-out of the reinforcement bar, in which the pulling force is produced by the compatibility disjoining movement of the opposite slab segment, the kinematic strain-displacement relationship along the crack is assumed to be defined by a modified bond-slip model for a pull-out test (see Figure 7).

Once the strains and tensile forces along the mid-crack are determined, the balancing distribution of compression forces along the mid-crack can be set and it is possible to calculate the in-plane bending moments at the compression center.

Both, Equation (1) and Equation (2), are highly nonlinear equations which can only be solved by means of an iterative procedure: initial values for $\mu(0)$ and $y_{0}$ are chosen in order to set a membrane forces distribution. In general, both equations are not fulfilled and new values of $\mu(0)$ and $y_{0}$ are assumed, iterating until both conditions are met. At the end, a distribution of membrane forces and bending moments along the yield lines for every deflected state of the slab, which satisfy kinematics and equilibrium conditions, is obtained. 

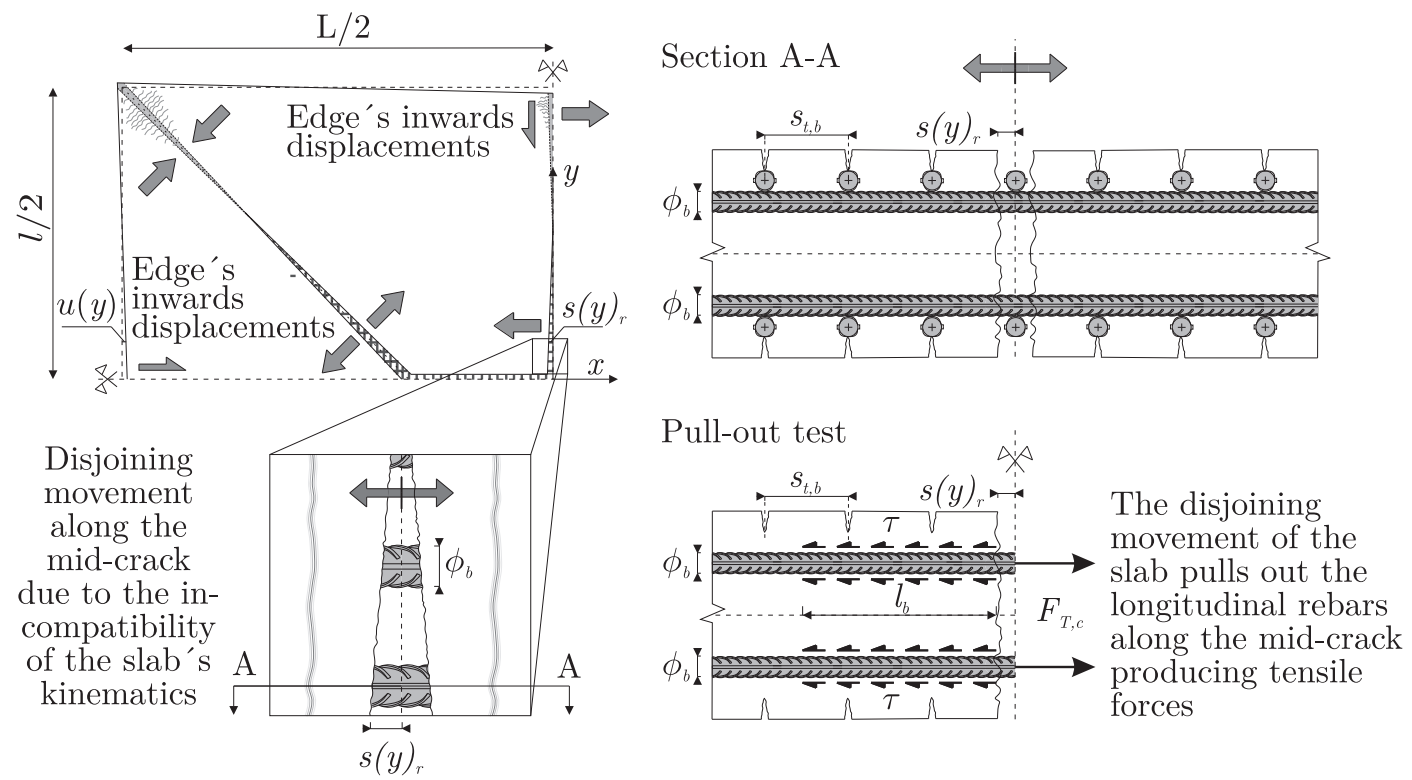

Figure 7. Similarity between a rebar pull-out test and the disjoining movement along the slab's mid-crack

Finally, the enhancement of the slab's load-bearing capacity due to the development of membrane forces is estimated. This enhancement is produced by two different mechanism. On the one hand, the $M-N$ interaction, which increases the ultimate bending capacity of compressed sections but decreases the capacity of sections subjected to tension. On the other hand, the tensile forces at the slab's centre combined with the deflections produce positive bending moments along the slab's support which balance the negative bending moments created by the uniform load.

The maximum load-bearing capacity of the slab for every deflected state is calculated through bending moment equilibrium of each of the individual segments about the slabs' supports, considering the internal forces acting along the yield lines and supports at that moment. The yield lines are assumed to be stepped in the reinforcement directions, which, according to Johansen's yield criterion, results in no torsional moments and in-plane shear forces. Hence, only the vertical shear and axial forces as well as the bending moments are considered for the equilibrium.

The vertical shear forces acting along the yield lines are not determined by the previous derivations. In order to calculate these forces, they are first replaced by two statically equivalent forces, one at each end of the length of yield line. Afterwards, the total forces acting on a segment at a point of intersection of the adjacent straight portions of a yield line are grouped in nodal forces. At the end, the distribution of shear forces is simplified to a nodal force acting at the corner of each slab segment. Only the six nodal forces at the junction of the positive yield lines influence the moment 
equilibrium about the supports. Considering the symmetry of the slab and force equilibrium, these nodal forces are reduced to one unknown shear nodal force.

In order to estimate this unknown, the moment equilibrium of the slab's segments 1 and 2 (see Figure 6) is considered, obtaining two expressions for the balancing uniform load $q$, dependent on the unknown nodal force. Since this balancing uniform load must be equal for the whole slab, the two aforementioned expressions are equated, and the values of both, the nodal force and the balancing load $q$, are obtained.

\section{Failure Criteria}

Based on the results of different experimental tests, two possible failures for lateral unrestrained slabs have been implemented in this new approach:

- Concrete crushing at the compressive ring, which is assumed to occur when the strain at the barycentre fibre of the section is equal to the strain at maximum compressive strength. The strains' redistribution capacity in the cross section at this point is very small and therefore failure is likely to occur.

- Reinforcement rupture at the mid-crack of the slab. As the rebars' strains are obtained from the bond-slip relationship, the method assumes that failure occurs when the ultimate tensile strain of the steel is reached.

Once failure occurs, the slab is assumed to have reached its maximum loadcarrying capacity and the calculation of the load-deflection relationship is stopped.

\section{CONCLUSION}

Laterally unrestrained slabs reach a lower bound of the possible maximum loadbearing capacity of flat slabs. Their energy absorption capacity is a key parameter for robustness assessments and can be estimated through the load-deflection relationship. Different approaches have been described in the past, which offer incomplete solutions for this problem. Even analysis based on the FEM are inadequate for the ultimate strength prediction.

An alternative procedure, which is based in strong physical principles and models, and incorporates well-founded failure criteria, has been proposed. The basic assumptions and calculation procedure of this novel approach have been briefly described in this document. The complexity of this approach requires an iterative numerical algorithm in order to calculate the distribution of in-plane forces during the deformation process. Although no numerical results are provided in this paper, this method is expected to lead to accurate results and to correlate well with experimental data. 


\section{REFERENCES}

ASCE 7-10 (2010). Minimum Design Loads for Buildings and Other Structures.

Bailey, C. G. and Toh, W. S. (2007). "Small-scale concrete slab tests at ambient and elevated temperatures." Engineering Structures 29: 2775-2791.

Bailey, C.G. (2001). "Membrane action of unrestrained lightly reinforced concrete slabs at large displacements." Engineering Structures, no. 23: 470-483.

Cashell, K.A. (2009). Ultimate behaviour of floor slabs under extreme loading conditions. PhD Thesis, Imperial College, London.

Department of Defense of the U.S.A (2005). Unified Facilities Criteria (UFC). Design of Building to Resist Progressive Collapse.

European Committee for Standardization (2006). EN 1991-1-7:2006. Actions on Structures, Part 1-7: General Actions - Accidental Actions.

Hayes, B. (1968). "Allowing for membrane action in the plastic analysis of rectangular reinforced concrete slabs." Magazine of Concrete Research 20, no. 65: 205-212.

Herraiz, B. and Vogel, T. (2014). "Robustness of flat slab structures for sudden column failure scenarios." Proceedings of the 10th fib International PhD Symposium in Civil Engineering, Université Laval. Québec, Canada.

Johansen K. W. (1943). Brudlinieteorier. Copenhagen: Jul. Gjellerups Forlag.

Kemp K. O. (1967). "Yield of a square reinforced concrete slab on simple supports, allowing for membrane forces." The Structural Engineer 45, no. 7: 235-240.

Park R., Gamble W. L. (2000). Reinforced Concrete Slabs. 2nd Edition. New York: John Wiley \& Sons, Inc.

Sawczuk, A. and Winnicki, L. (1965). "Plastic behavior of simply supported reinforced concrete plates at moderately large deflections." International Journal of Solids and Structures 1: 97-111.

U.S. General Services Administration (2003). Progressive Collapse Analysis and Design Guidelines.

Vanderbilt M. D., Sozen M. A. and Siess C. P. (1963). "Deflection of reinforced concrete floor slabs." Research Project, University of Illinois Urbana, Illinois. 